Diabetologia 10, 469-474 (1974)

(C) by Springer-Verlag 1974

\title{
Circulating Proinsulin-Like Component in Man: \\ Increased Proportion in Hypoinsulinemic States
}

\author{
P. Gorden, C.M. Hendricks, and J. Roth \\ Diabetes Branch, National Institute of Arthritis, Metabolism and Digestive Diseases, \\ National Institutes of Health, Bethesda, USA
}

Received: April 5, 1974, and in revised form: June 27, 1974

\begin{abstract}
Summary. The proportion of total plasma immunoreactive insulin comprising the proinsulin-like component was determined in $\mathbf{5}$ diabetic subjects manifesting fasting hyperglycemia, severe glucose intolerance, and insulinopenia, and also in one insulinopenic patient both before and after removal of a phaeochromocytoma. The proinsulin-like component comprised a mean of $37 \%$ (range $30-50 \%$ ) of the total immunoreactive insulin in the basal state, $27 \%$ (range $20-32 \%$ ) at $15 \mathrm{~min}$, and $32 \%$ (range $23-50 \%$ ) 120 min after $100 \mathrm{~g}$ of oral glucose. These values are significantly higher than in normal subjects or patients with hyperinsulinemic responses (excepting
\end{abstract}

patients with insulinoma). Our studies suggest that diseases that affect the B-cell's ability to store insulin or prevent the secretory granule of the B-cell from undergoing full maturation will be associated with an increased secretion from immature granules, that contain a higher percentage of proinsulin-like components. The proportion of the total immunoreactive insulin comprising the proinsulin-like component is, therefore, a reflection of the integrity of the B-cell granule.

Key words: Proinsulin-like component in hypoinsulinemia.
Following the description of proinsulin by Steiner and Oyer [2], we demonstrated that plasma immunoreactive insulin (IRI) comprises at least two discrete components [3]. The plasma "big" insulin component has subsequently been shown to comprise several factors which are all related to pancreatic proinsulin and is referred to as the proinsulin-like component (PLC), while the plasma "little" insulin component has been found to be indistinguishable from pancreatic insulin $[4-10]$.

Although the role of proinsulin in the biosynthesis of insulin is clear, the significance of the circulating PLC remains unclear. In our initial study we reported that the "big", or PLC, from a normal subject comprised about $20 \%$ of the total plasma IRI [3]. Subsequent reports of our own, $[11,12]$ as well as reports from a number of other laboratories $[10,13,14]$ using gel filtration techniques, have confirmed that the PLC comprises an average of about $20 \%$ (range $10-30 \%$ ) of the total basal IRI in normal subjects. Aside from patients with insulinomas, the other major groups of patients that have been studied are hyperinsulinemic, usually insulin resistant patients, e.g. obesity with and without glucose intolerance, acromegaly, and Cushing's disease. While these patients have a higher absolute concentration of the PLC, commensurate with their high total insulin concentration, the PLC comprises approximately the same percentage of the total IRI as in normal subjects $[10$, $12,13,15]$. A higher proportion of the biologically less active PLC cannot, therefore, account for the insulin resistance seen in these patients.
Though the range of values is wide, it is clear that the highest percent PLC is seen in patients with benign or ma!ignant insulin secreting tumors $[12-16]$. In our original study, in a single diabetic subject with severe glucose intolerance and relative hypoinsulinemia, we found that the PLC, in multiple samples, comprised from one-third to one-half of the total IRI [3]. It has also been shown that patients with hypokalemia and low total insulin concentrations, have a higher proportion of the PLC than is found in either normal or hyperinsulinemic subjects [17].

We now present further evidence that most hypoinsulinemic states, regardless of etiology, are characterized by a higher percentage of the PLC and suggest that in these patients, as well as in patients with an insulinoma, the competence of the secretory granule of the B-cell to store insulin may be the primary factor that determines the proportion of the plasma PLC in disease states in man.

\section{Materials and Methods}

Five non-obese male patients with diabetes mellitus were studied as inpatients on a metabolic unit. Four of the five ranged in age from $45-55$ years and one patient (RAM) was 68 years of age. One non-obese 50 year-old female patient with both biochemical and histologic evidence of pheochromocytoma was studied before and after surgical removal of the tumor. All six patients had normal renal function as assessed by blood urea nitrogen (BUN) 
and serum creatinine, and all had normal serum electrolytes and liver function, as determined by standard laboratory procedures.

Each patient consumed a diet that contained at least $300 \mathrm{~g}$ of carbohydrate for at least three days prior to a $100 \mathrm{~g}$ oral glucose tolerance test, which was performed in the morning after an overnight fast. None of the patients had received insulin therapy prior to the test, but all became insulin requiring shortly after these studies.

Blood glucose and total plasma IRI were determined as previously described [3, 12]. The plasma insulin components were separated by gel filtration. $7 \mathrm{ml}$ of plasma or less (the concentration of total IRI determined the volume of plasma required) were applied to a $1.5 \times 90 \mathrm{~cm}$ column of G-50 Sephadex (fine) and eluted with $0.05 \mathrm{M}\left(\mathrm{NH}_{4}\right)_{2} \mathrm{CO}_{3}, \mathrm{pH} 8.6$, as previously described $[12,18]$. The resultant fractions were lyophilized to dryness, dissolved in the diluent for the radioimmunoassay and the concentration of IRI determined. All results are expressed in terms of a porcine insulin standard and can be compared only to other workers using porcine or human insulin standards and gel filtration separation.

\section{Results}

All five diabetic patients had a marked elevation of the fasting blood glucose (range $170-320 \mathrm{mg} / 100 \mathrm{ml}$ ) and demonstrated severe glucose intolerance (peak glucose $350 \mathrm{mg} / 100 \mathrm{ml}-500 \mathrm{mg} / 100 \mathrm{ml}$ ) during a $100 \mathrm{~g}$ oral glucose tolerance test. All five patients exhibited a severely impoverished insulin response, with three of the patients showing less than a $25 \mu \mathrm{U} / \mathrm{ml}$ peak value and the other two exhibiting no greater than a $50 \mu \mathrm{U} / \mathrm{ml}$ response, in the presence of very high concentrations of blood glucose (Figs. 1 and 2).

When plasma was filtered over G-50 Sephadex, two discrete immunoreactive components were seen (Figs. 1 and 2). The less retarded component represented the PLC while the lower molecular weight immunoreactive component represented the insulinlike component. The highest proportion of the PLC was seen in the basal state as has previously been reported for all other conditions [12]. There was little change in the concentration of the PLC at $15 \mathrm{~min}$ after oral glucose and only a small change in the percent PLC, commensurate with the lack of significant change in total insulin concentration. By two hours after oral glucose there was a rise in the concentration of the PLC, and a return of the percent PLC to values similar to those seen in the basal state (Fig. 2).

Patients with pheochromocytoma may have glucose intolerance associated with hypoinsulinemia $[19,20]$. Our patient with pheochromocytoma demonstrated marked fasting hyperglycemia, severe glucose intolerance, and a very low total insulin response. When plasma was fractionated, proportions of the
PLC were similar to the hypoinsulinemic diabetic subjects. When the pheochromocytoma was surgically removed, all clinical signs of the disease disappeared including the glucose and insulin abnormalities. By one year after removal of the tumor the fasting blood glucose had returned to normal, glucose tolerance was near normal (glucose at $2 \mathrm{hrs}$ after oral glucose $=$ $150 \mathrm{mg} / 100 \mathrm{ml}$ ) and the total insulin response was appropriate for the glucose values (Fig. 3). Nor-
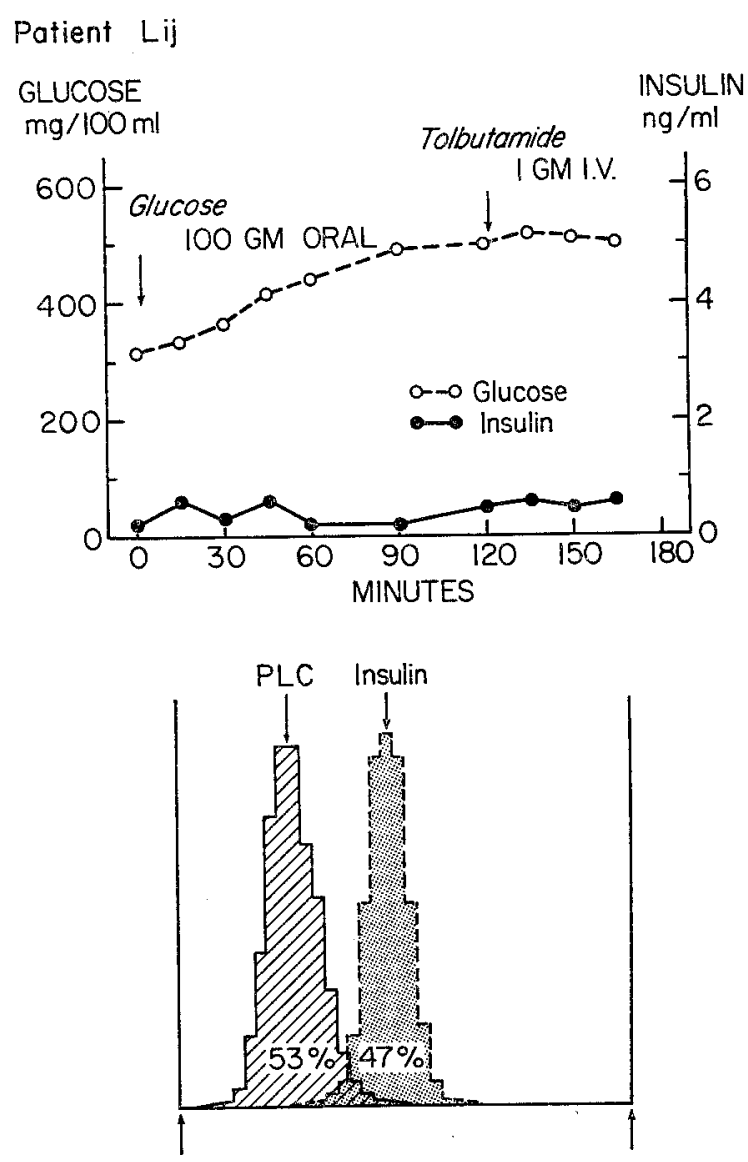

Fig. 1. $100 \mathrm{~g}$ oral glucose tolerance test in diabetic patient. (Top) Glucose and total insulin responses. Note there was little change in the total insulin concentration with severe hyperglycemia or with intravenously administered tolbutamide in the presence of hyperglycemia. (Insulin concentration in $\mathrm{ng} / \mathrm{ml} \times \mathbf{2 5}=\mu \mathrm{U} / \mathrm{ml}$.) (Bottom) G-50 Sephadex gel filtration pattern of plasma drawn at 120 min. $250 \mathrm{ml}$ of heparinized plasma were prefiltered on a $8 \times 100 \mathrm{~cm}$ column and the fractions comprising the proinsulin-like (PLC) and insulin-like component (Insulin) were separately pooled, concentrated and individually filtered on a $1.5 \times 90 \mathrm{~cm}$ G-50 (fine) Sephadex column [12, 18]. The filtration pattern for each component between markers of ${ }^{125} \mathrm{I}$-albumin $(\uparrow)$ left and ${ }^{125} \mathrm{I}(\uparrow)$ right are shown. The total IRI concentration from each fraction (vertical axis) is plotted as a function of the elution volume of the fraction. When these partially purified fractions were separately pooled and subjected to further gel filtration, [5] immunochemical dilution, [5] and radioreceptor assay [21-23] they were indistinguishable from similar preparations obtained from normal or hyperinsulinemic patients 
malization of the glucose and total insulin concentration resulted in a fall in the percent $\mathrm{PLC}$ in the basal state and at 15 min after oral glucose, but there was no change $120 \mathrm{~min}$ after oral glucose. The lack of change in the percent PLC 120 min after oral glucose is commensurate with the almost identical total insulin concentrations at this time in both the pre- and postoperative samples. insulinemic responses, and are comparable to values seen in insulinopenic patients with hypokalemia (Fig. 4). The low total IRI response in these patients results from a lower concentration of the PLC as well as the insulin component, compared to normal or hyperinsulinemic patients, but the relative proportion of the total IRI comprising the PLC is greater in the hypoinsulinemic patients.

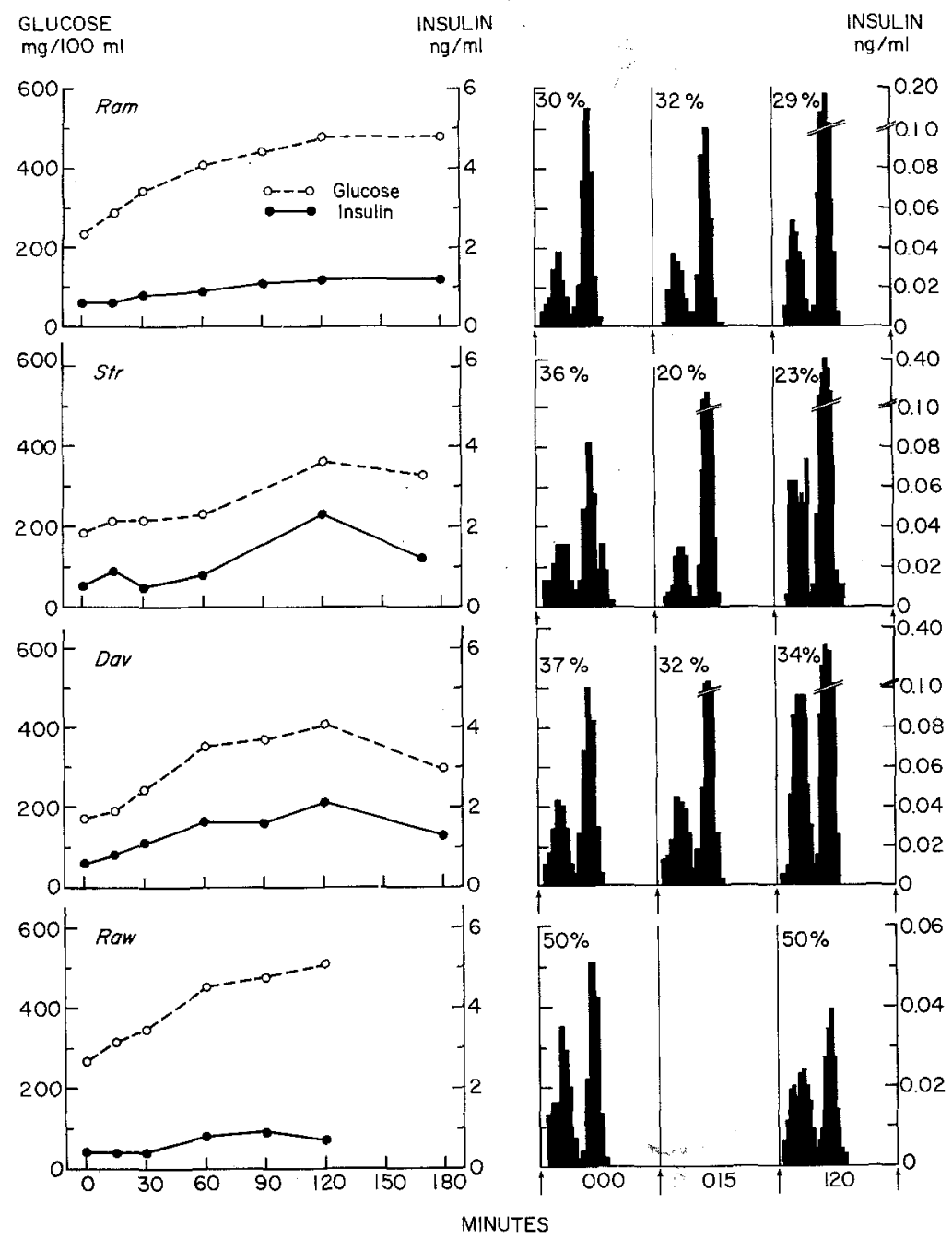

Fig. 2. $100 \mathrm{~g}$ oral glucose tolerance test in diabetic patients. (Left panel) Glucose and total insulin responses. (Right panel) G-50 Sephadex gel filtration pattern carried out on a $1.5 \times 90 \mathrm{~cm}$ column. ( $\uparrow$ ) same as Fig. 1

The mean percent of PLC for the four diabetic patients (patient Lij (Fig. 1) not included because he was studied at only a single time point) and the one patient with a pheochromocytoma are as follows: in the basal state, $37 \%$ (range $30-50 \%$ ); 15 min after oral glucose, $27 \%$ (range $20-32 \%$ ); and at $120 \mathrm{~min}, 32 \%$ (range $23-50 \%$ ). These values are distinctly higher than those seen in normal subjects or in patients with glucose intolerance and hyper-
To determine whether the PLC from a patient with severe hypoinsulinemia had similar properties to material obtained from normal subjects or hyperinsulinemic patients, the individual components were isolated from a large volume of plasma (Fig. 1). The partially purified, proinsulin-like and insulin-like components in this severely hypoinsulinemic patient were found to have the same gel filtration [5], immunochemical [5] and radioreceptor properties [21- 
23] as material obtained from normal or hyperinsulinemic subjects.

\section{Discussion}

We have found that patients with clinical conditions characterized by glucose intolerance associated with hypoinsulinemia have a higher proportion of their total IRI in the proinsulin-like form. This includes the patient in our initial report whose "big"
PLC, commensurate with their very small change in total insulin response [24]. This suggested that potassium deficiency per se was not the major factor and that the common denominator between the hy. pokalemic patients and the patients in this report is hypoinsulinemia. Thus, it is patients with insulinoma and patients with hypoinsulinemia who have the highest percent PLC.

Before attempting to relate the concentration or proportion of a hormone to an event involving secretion, the metabolism of that hormone must be care-

Patient Wag

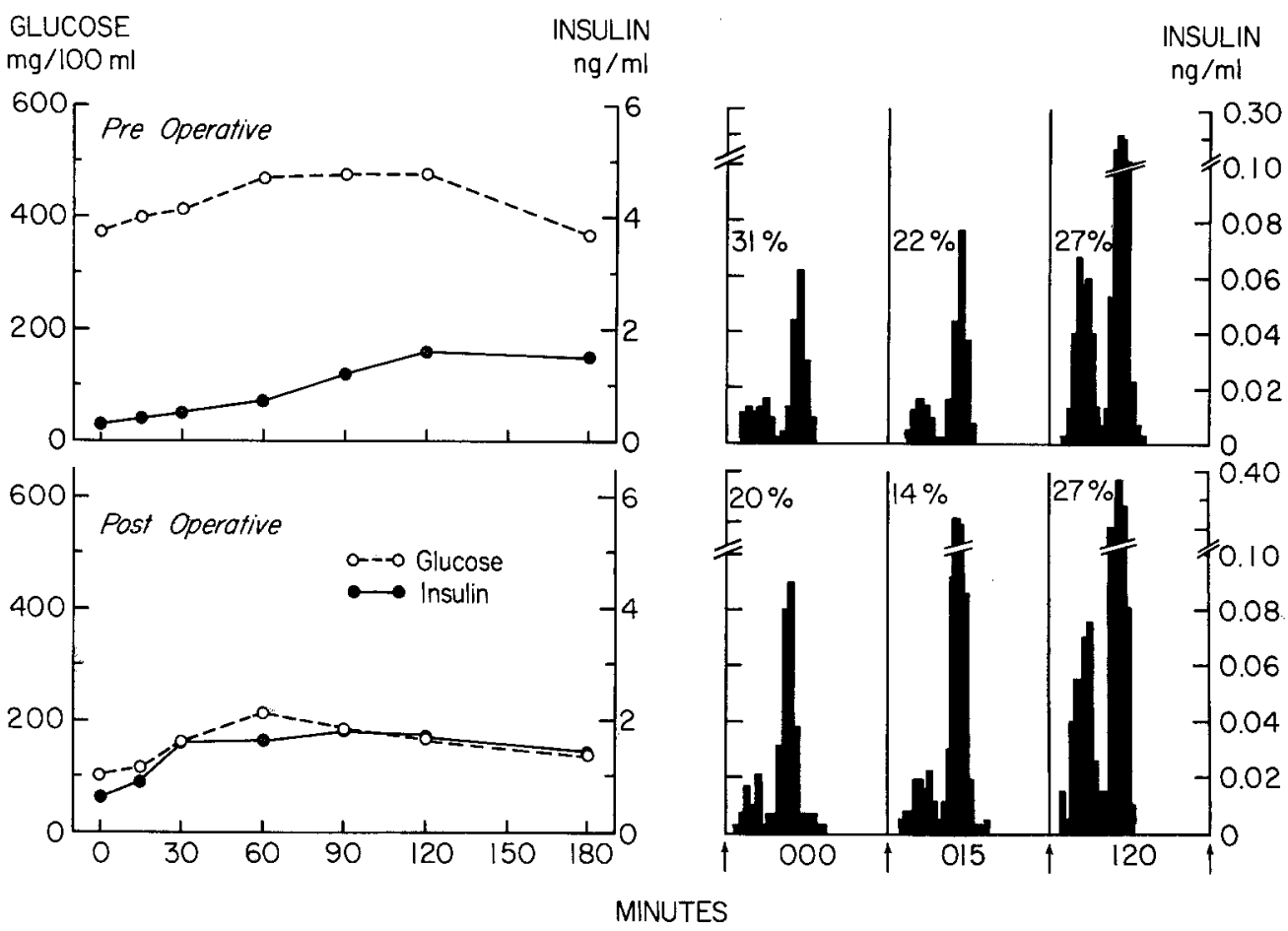

Fig. 3. $100 \mathrm{~g}$ oral glucose tolerance test in patient with pheochromocytoma. Top panel represents glucose, total insulin responses and G-50 Sephadex gel filtration patterns preoperatively and the bottom panel represents the same studies one year after removal of the tumor

insulin who, in fact, had severe ghucose intolerance with hypoinsulinemia [3]. These values are lower than are seen in many patients with an insulinoma, but are greater than those usually seen in normal subjects or in hyperinsulinemic patients. Furthermore, the increased percent PLC can be decreased in individual patients when their impoverished insulin secretion is improved [17].

Following our demonstration that hypokalemic patients with decreased total insulin responses had a relatively high proportion of the PLC, we attempted to reproduce this phenomenon in normal subjects by experimental potassium depletion. The normal subjects, though significantly potassium depleted and hypokalemic, had essentially no change in their percent fully considered. The major sites of degradation of proinsulin and insulin are different, proinsulin being degraded primarily by the kidney and insulin mainly by the liver $[25,26]$. This is compatible with a higher percentage of the PLC in patients with renal disease than in patients with hepatic disease [27]. Furthermore, exogenously administered insulin disappears faster from the plasma of animals $[26,28]$ and man [29] than does exogenously administered proinsulin, and endogenous insulin disappears faster than the endogenous PLC from the plasma of patients undergoing removal of islet cell adenomas $[6,30]$. The slower degradation rate of the plasma PLC accounts in part for the fact that the percent PLC may be $4-5$ times greater in plasma than in the pancreas. While the peripheral metabolism of proinsulin and insulin is 
different, there is no evidence that the metabolism of the PLC per se is altered in any disease state other than uremia. The metabolism of insulin is unaltered over the physiologic range of insulin concentration [25] and it seems reasonable to speculate that the same is true for proinsulin. Since the connecting peptides of animal proinsulins are very different from human proinsulin, definitive proof of this point in man must await sufficient supplies of human proinsulin.

Proinsulin is synthesized on the ribosome of the B-cell and then transferred to the Golgi region, where the events in secretory granule formation begin [31, 32]. As the immature $\beta$-granule goes through the incubation medium as is found in plasma; this amount is several fold greater than the percent PLC in the tumor [12]. In a detailed and systematic study Creutzfeldt and associates have found that the proportion of proinsulin found in insulinomas is proportional to the relative number of beta granules and that degranulation is greatest in malignant insulinomas [33]. In addition, these workers have demonstrated an increase in the turnover rate of both proinsulin and insulin in human insulinoma tissue as compared to normal pancreatic islets [34]. Furthermore, patients with malignant insulinomas tend to have the highest proportions of the PLC in plasma [16]. These data, taken together, suggest that diseases that affect the

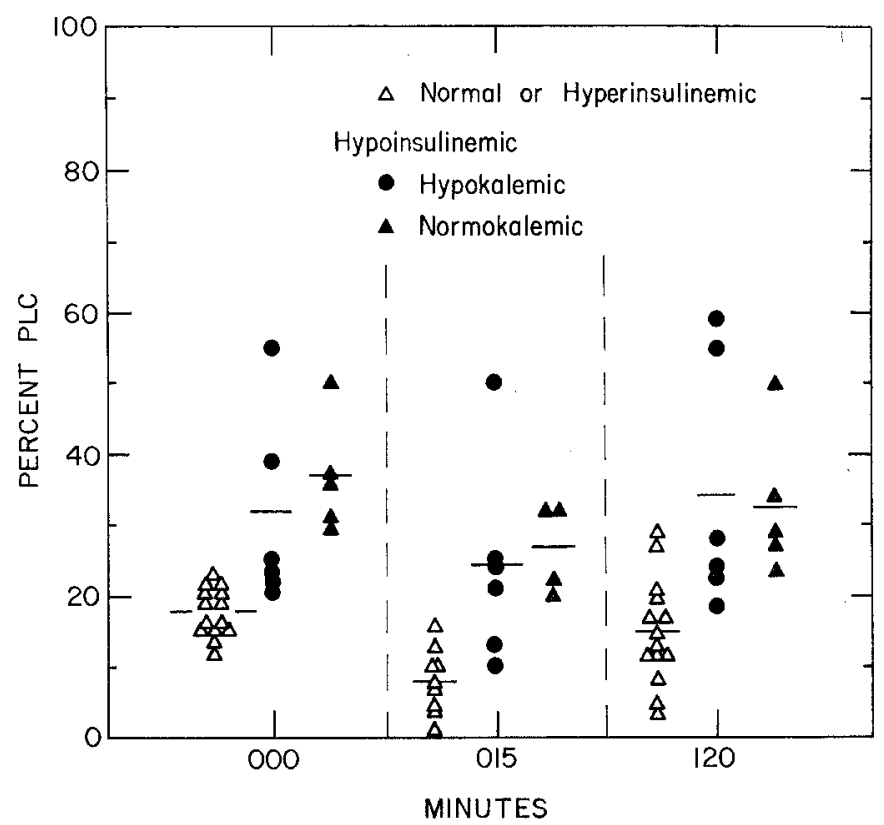

Fig. $4.100 \mathrm{~g}$ oral glucose tolerance test. The mean and range of values for normal or hyperinsulinemic subjects $(\triangle)$, hypokalemic hypoinsulinemic subjects (-) as have been previously reported [12, 17] are compared to the hypoinsulinemic patients described in this report $(\mathbf{A})$

process of maturation, proinsulin is converted to insulin. Thus, the immature secretory granule is relatively rich in proinsulin. The integrity of the $\beta$ granule is, therefore, essential for the normal process of storage and secretion of insulin. In the normal rat islet, in vitro, this proceeds in an orderly fashion and insulin is predominantly secreted into the incubation medium [32]. Only small amounts of proinsulin appear in the media after about two hours of incubation and there is no apparent preferential secretion of proinsulin.

The events that characterize insulin and proinsulin secretion from the normal islet may not completely apply to the pathologic islet. A high percentage of the PLC is seen in the plasma of golden hamsters who harbor transplantable islet cell tumors. Furthermore, when slices of these tumors are incubated in vitro a similar proportion of the PLC appears in the bota cell's ability to store and to secrete insulin or prevent the beta granule from undergoing full maturation will be associated with an increased secretion from immature granules, which contain a higher percent of proinsulin. This does not exclude the possibility that islet cell tumors may also synthesize proinsulin at an increased rate, or that under some circumstances nongranular secretion may occur.

Thus, in hypoinsulinemic patients, with a constant stimulus to the B-cell to secrete insulin, the proportion that will be secreted in the pro-insulin form will depend upon the relative number of granules and the functional integrity of the secretory apparatus. A similar set of circumstances might occur in patients with insulinoma even though insulin secretion may occur spontaneously. Finally, our data suggest that the increased proportion of the PLC seen in hypoinsulinemic patients is a reflection of the defect in 
the $B$-cell to store and secrete insulin rather than of a specific disease process that leads to this defect.

\section{References}

1. Gorden, P., Roth, J.: Circulating proinsulin-like component: An increased proportion in severe hypoinsulinemic states in man. Clin. Res. 20, 623 (abstract) (1972)

2. Steiner, D.F., Oyer, P.E.: The biosynthesis of insulin and a probable precursor of insulin by a human islet cell adenoma. Proc. nat. Acad. Sci. (Wash.) 57, 473480 (1967)

3. Roth, J., Gorden, P., Pastan, I.: "Big insulin": a new component of plasma insulin detected by immunoassay. Proc. nat. Acad. Sci. (Wash.) 61, 138-145 (1968)

4. Sherman, B.M., Gorden, P., Roth, J., Freychet, P.: Circulating' insulin: the proinsulin-like properties of "big" insulin in patients without islet cell tumors. J. clin. Invest. 50, $849-858$ (1971)

5. Gorden, P., Freychet, P., Nankin, H.: A unique form of circulating insulin in human islet cell carcinoma. J. clin. Endocr. 33, 983-987 (1971)

6. Gorden, P., Roth, J., Freychet, P., Kahn, R.: The circulating proinsulin-like components. Diabetes 21 (Suppl. 2), 673-677 (1972)

7. Gutman, R. A., Lazarus, N.R., Recant, L.: Electrophoretic characterization of circulating human proinsulin and insulin. Diabetologia 8, 136-140 (1972)

8. Gorden, P., Roth, J., Hendricks, C.M., Kahn, C.R.: The plasma proinsulin-like components. Israel J. Med. Sci. (in press) (1974)

9. Rubenstein, A.H., Cho, S., Steiner, D.F.: Evidence for proinsulin in human urine and serum. Lancet 1968 I, 1353

10. Melani, F., Rubenstein, A.H., Steiner, D.F.: Human serum proinsulin. J. clin. Invest. 49, 497-507 (1970)

11. Gorden, P., Roth, J.: Plasma insulin: Fluctuations in the "Big" insulin component in man following glucose and other stimuli. J. clin. Invest. 48, 2225-2234 (1969)

12. Gorden, P., Sherman, B., Roth, J.: Proinsulin-like component of circulating insulin in the basal state and in patients and hamsters with islet cell tumors. J. clin. Invest. 50, 2113-2122 (1971)

13. Gutman, R.A., Lazarus, N.R., Penhos, J.C., Fajans, S., Recant, L.: Circulating proinsulin-like material in patients with functioning insulinomas. New Engl. J. Med. 284, $1003-1008$ (1971)

14. Sherman, B.M., Pek, S., Fajans, S. S., Floyd, J.C., Jr., Conn, J.W.: Plasma proinsulin in patients with functioning pancreatic islet cell tumors. J. clin. Endocr. $35,271-280(1972)$

15. Goldsmith, S.J., Yalow, R.S., Berson, S.A.: Significance of human plasma insulin Sephadex fractions. Diabetes 18, 834 - 839 (1969)

16. Schein, P.S., DeLellis, R. A., Kahn, C. R., Gorden, P., Kraft, A. R.: Islet cell tumors: Current concepts and management. Ann intern. Med. 79, 239-257 (1973)

17. Gorden, P., Sherman, B.M., Simopoulos, A.P.: Glucose intolerance with hypokalemia: An increased proportion of circulating proinsulin-like component. J. clin. Endocr. 34, 235-240 (1972)

18. Gorden, P., Hendricks, C.M.: The measurement of plasma insulin and proinsulin-like components. In: Croll, M.N., Wallner, R., Honda, T. (Eds.): New Techniques in Tumor Localization and Radioimmunoassay, pp. 17-24. New York: John Wiley \& Son. 1974

19. Wilber, J.F., Turtle, J.R., Crane, N.A. : Inhibition of insulin secretion by a pheochromocytoma. Lancet 1966 II, 733

20. Vance, J.E., Buchanan, K.D., O'Hara, D., Williams,
R.H., Porte, D., Jr.: Insulin and glucagon responses in subjects with pheochromocytoma: Effect of alpha adrenergic blockade. J. clin. Endocr. 29, 911-916 (1969)

21. Gavin, J.R., III, Kahn, C.R., Gorden, P., Roth, J., Neville, D.M., Jr., Humbel, R.E.: Radioreceptor assay for insulin: Application to plasma components, pancreatic components and non-immunoreactive insulin-like materials. (abstract 70) Diabetes 22 (suppl.) $306(1973)$

22. Gavin, J.R., III, Gorden, P., Roth, J., Archer, J.A., Buell, D. N.: Characteristics of the human lymphocyte insulin receptor. J. biol. Chem. 248, 2202-2207 (1973)

23. Gorden, P., Gavin, J.R., III, Kahn, C.R., Archer, J.A., Lesniak, M., Hendricks, C., Neville, D.M., Jr., Roth, J.: Application of radioreceptor assay to circulating insulin, growth hormone, and to their tissue receptors in animals and man. Pharmacol. Rev. 25, 179-187 (1973)

24. Gorden, P.: Glucose intolerance with hypokalemia: Failure of short-term potassium depletion in normal subjects to reproduce the glucose and insulin abnormalities of clinical hypokalemia. Diabetes 22, 544$551(1973)$

25. Rubenstein, A.H., Pottenger, L.A., Mako, M., Getz, G.S., Steiner, D.F.: The metabolism of proinsulin and insulin by the liver. J. clin. Invest. 51, 912-921 (1972)

26. Katz, A.I., Rubenstein, A.H.: Metabolism of proinsulin, insulin, and C-peptide in the rat. J. elin. Invest. 52, 1113-1121 (1973)

27. Mako, M., Block, M., Starr, J., Nielsen, E., Friedman, E., Rubenstein, A.: Proinsulin in chronic renal and hepatic failure: A reflection of the relative contribution of the liver and kidney to its metabolism. Clin. Res. 21, 631 (abstract) (1973)

28. Stoll, R.W., Touber, J.L., Winterscheid, L.C., Ensinck, J.W., Williams, R.H.: Hypoglycemic activity and immunological half-life of porcine insulin and proinsulin in baboons and swine. Endocrinology 88, $714-717$ (1971)

29. Tompkins, C.V., Srivastava, M.C., Sonksen, P.H., Nabarro, J.D. N.: A comparative study of the distribution and metabolism of monocomponent human insulin and porcine proinsulin in man. Biochem. J. 125, 64 (1971)

30. Starr, J.I., Katz, A., Steiner, D.F., Rubenstein, A.H.: Metabolism of endogenous proinsulin in man. Diabetes 21 (Suppl. 1), 347 (1972)

31. Kemmler, W., Steiner, D.S.: Conversion of proinsulin to insulin in a subcellular fraction from rat islets. Biochem. biophys. Res. Commun. 41, 1223-1230 (1970)

32. Sando, H., Borg, J., Steiner, D.F.: Studies on the secretion of newly synthesized proinsulin and insulin from isolated rat islets of Langerhans. J. clin. Invest. 51, $1476-1485(1972)$

33. Creutzfeldt, W., Arnold, R., Creutzfeldt, C., Deuticke, U., Frerichs, H., Track, N.S.: Biochemical and morphological investigations of 30 human insulinomas: Correlation between the tumor content of insulin and proinsulin-like components and the histological and ultrastructural appearance. Diabetologia 9, 217-231 (1973)

34. Creutzfeldt, C., Track, N.S., Creutzfeldt, W.: In vitro studies of the rate of proinsulin and insulin turnover in seven human insulinomas. Europ. J. clin. Invest. 3, $371-384$ (1973)

Phillip Gorden, M.D.

Clinical Director

National Institute of Arthritis

Metabolism \& Digestive

Diseases, BId, 10, Room 9N-222

Bethesda, Maryland 20014

USA 